\title{
Cochlear implantation in South Africa (part 1)
}

\author{
A Bhamjee, ${ }^{1}$ MA (Audiology) (D); F Mahomed-Asmail, ${ }^{1}$ DPhil (Communication Pathology); J Perold, ${ }^{2}$ MSc (Audiology); \\ J W Loock, ${ }^{3}$ MB ChB; T le Roux, ${ }^{1}$ DPhil (Communication Pathology) \\ ${ }^{1}$ Department of Speech-Language Pathology and Audiology, Faculty of Humanities, University of Pretoria, South Africa \\ ${ }^{2}$ Tygerberg Hospital Stellenbosch University Cochlear Implant Unit, Cape Town, South Africa \\ ${ }^{3}$ Division of Otorhinolaryngology, Faculty of Medicine, Stellenbosch University, Cape Town, South Africa
}

Corresponding author: T le Roux (talita.leroux@up.ac.za)

Cochlear implantation is a timeous and cost-effective solution for severe-profound sensorineural hearing loss, and has transformed the lives of many individuals with significant hearing loss. The advent of cochlear implantation has meant that, for the first time, one of the senses (hearing), having been entirely lost, can be restored. This, the first of a two-part series on cochlear implantation in South Africa (SA) puts global (and especially SA) hearing loss in perspective, sets out the principles of cochlear implantation and briefly sketches the history of this world-changing technology.

S Afr Med J 2021;112(1):8-10. https://doi.org/10.7196/SAMJ.2021.v111i1.16017

Hearing loss is the fourth-most common cause of disability worldwide, ${ }^{[1,2]}$ and the second-most disabling condition on the list of non-fatal disabling conditions within low- and middleincome countries (LMICs). ${ }^{[3]}$ It is also reportedly the most prevalent childhood sensory disorder globally. ${ }^{[4]}$ Disabling hearing loss is defined as a hearing loss exceeding $40 \mathrm{dBHL}$ in the better-hearing ear in adults (aged $\geq 15$ years), and $30 \mathrm{dBHL}$ in the better-hearing ear in children $\left(0\right.$ - 14 years) ${ }^{[5]}$ Untreated hearing loss has farreaching adverse consequences on an individual's language, cognitive and social functioning, as well as educational and employment opportunities ${ }^{[6-10]}$ Hearing loss is also extremely isolating. Helen Keller famously said that if she had to choose between being blind and deaf, she would rather choose blind, since 'blindness separates people from things, deafness separates people from people.

Alarmingly, more than half of the world's individuals with hearing loss reside within LMICs across developing world regions, such as Asia Pacific, South Asia and sub-Saharan Africa. ${ }^{[2,5,11]}$ Globally, of the estimated 430 million individuals (5.5\% of the global population) who have hearing loss, 60.5 million $(0.8 \%)$ of these individuals have either severe or profound hearing loss or complete deafness. ${ }^{[1]}$ Furthermore, of those global 430 million individuals, 39.9 million (3.6\%) individuals with moderate or worse hearing loss populate the African continent. ${ }^{[11]}$

There is an overall dearth of published data on the prevalence of hearing loss in South Africa (SA). ${ }^{[12]}$ A national census on disability conducted in 2011 revealed that $0.7 \%$ of the population aged $>5$ years experiences severe hearing loss. ${ }^{[13]}$ The limited population studies available for emerging populations (including African nations) indicate that the prevalence of profound hearing loss in children in emerging populations is significantly higher than the estimated prevalence $(20-30 \%)$ in the developed world. ${ }^{[14-17]}$ The burden of disabling hearing loss needs to be addressed at a national level in SA. ${ }^{[5,18]}$

\section{Cochlear implantation as a treatment option for severe-profound sensorineural hearing loss}

Cochlear implantation is a well-established, cost-effective intervention for individuals with severe-profound sensorineural hearing loss
(SNHL) who derive insufficient benefit from acoustic amplification (hearing aids).

Cochlear implants (CIs) function by bypassing damaged hair cells in the cochlea and directly stimulating the auditory nerve's functional neurons, ${ }^{[19]}$ thus providing the brain with access to sound.

Cochlear implantation is possible and successful because of several remarkably fortuitous anatomical factors. The first is that, in SNHL, the site of the pathology is overwhelmingly the hair cells of the cochlea, with the auditory nerve and central connections functional. Therefore, bypassing the hair cells and stimulating the auditory nerve is almost always possible. Secondly, the cochlea is a fluid-filled, coiled-up tube into which an electrode can easily be introduced. The auditory and neural elements are arranged in a logical, tonotopic manner and are therefore easy to work with. The position of the cochlea deep to and anterior to the mastoid air-cell system, and the orientation of the cochlea, make it relatively easy for a surgeon to access the round window and basal turn of the cochlea and introduce and advance the electrode. Finally, the incredible 'plasticity' of the brain makes it able to use the man-made electronic stimulus provided by the device and 'learn' how to optimise its use.

The CI system's basic components comprise a surgically implantable receiver-stimulator and electrode, and an externally worn speech processor (Fig. 1). ${ }^{[20]}$ The (external) speech processor is held over the (totally implanted) receiver-stimulator by a magnet. The microphone of the speech processor receives the sound from the environment, which is then converted into digital signals by the speech processor. The digital signals are transferred through the skin to the internal receiver-stimulator via the transmitter coil. The receiver-stimulator turns the digital signals into electrical signals that are sent to the electrode array in the cochlea to stimulate the hearing nerve fibres. This process occurs instantaneously.

The remarkable long-term and life-changing benefits of paediatric and adult cochlear implantation, which enable reintegration into the 'hearing world, are well documented. Early paediatric cochlear implantation increases the probability of a child's potential to develop age-related speech and language skills owing to appropriate, early access to sound. ${ }^{[21-27]}$ In addition, it further contributes toward improved psychosocial and educational outcomes in paediatric 


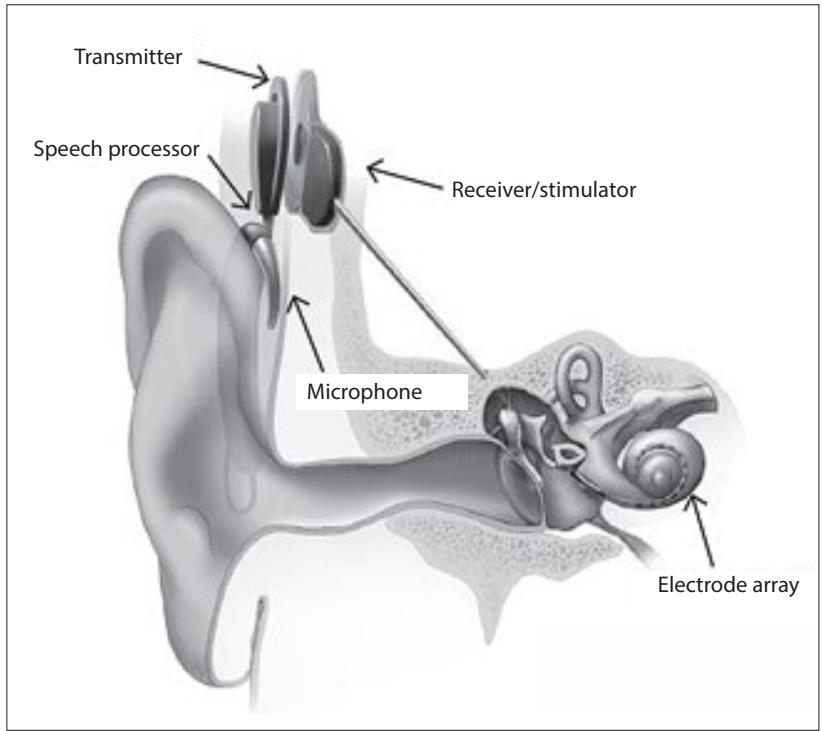

Fig. 1. Ear with a cochlear implant. ${ }^{[20]}$

CI recipients. ${ }^{[28]}$ Similarly, adult cochlear implantation not only results in enhanced auditory and speech perception abilities, but is also proven to have a positive impact on adult CI recipients' social functioning, self-esteem and educational and vocational opportunities. ${ }^{[29-33]}$

\section{The history of cochlear implantation internationally}

On 9 January 1961, Dr William F. House (otologist) and Dr John Doyle (neurosurgeon) performed the first true CI surgery by inserting a single-channel electrode inside the cochlea through the round window. ${ }^{[34]}$ Following the Food and Drug Administation (FDA)'s first approval of the single-channel implant for adults in $1984,{ }^{[35]}$ remarkable and rapid improvements to CIs were made. In 1985, the multichannel implant received FDA approval, and it was Prof. Graeme Clark who performed the first commercialised multichannel CI surgery. ${ }^{[34]}$ Initially, FDA approval for cochlear implantation was limited to adults - understandably so, given that it was fairly new and unknown technology. It was only in 1990 that FDA approval was obtained for multichannel cochlear implantation for children. ${ }^{[36]}$ Initially, the minimum age for children to receive a CI was 2 years; it then decreased to 18 months in 1998, and finally 12 months in 2000. ${ }^{[36]}$ Approximately 736900 registered CI devices have been implanted globally as of December 2019. ${ }^{[20]}$

\section{The history of cochlear implantation in South Africa}

Within sub-Saharan Africa, SA is currently the only country with an established national CI platform and existing infrastructure for cochlear implantation. ${ }^{[37]}$ The first CI programme was established in 1986 at Stellenbosch University's otorhinolaryngology department, situated at Tygerberg Hospital in the Western Cape Province. On 4 November 1986, the first multichannel cochlear implantation procedure was performed in SA by the pioneers of CIs in SA, Prof. Derrick Wagenfeld (otorhinolaryngologist and head of the otorhinolaryngology department) and Mrs Alida Müller (audiologist). Since then, more than 2877 hearing-impaired individuals have received implants countrywide (South African
Cochlear Implant Group 2019: Annual Report - unpublished society document).

\section{The professionals involved in cochlear implantation}

A multidisciplinary team approach is essential for cochlear implantation. Each professional on the multidisciplinary CI team provides a distinct clinical outlook. Communication between the team members ensures well-co-ordinated patient evaluation and implantation. ${ }^{[38]}$ Sound determination of CI candidacy necessitates the successful collaboration of various professionals involved in cochlear implantation, with each professional requiring adequate knowledge of the other team members' scope of practice within the field of CIs. A CI programme comprises the following essential personnel: otologists; audiologists; and rehabilitation specialists such as speech-language therapists and/or auditory-verbal therapists. ${ }^{[39-41]}$

Other additional professionals who should either be part of the CI team, or to whom the team should at least have access, include radiologists, neurologists, paediatricians, vestibular specialists, tinnitus specialists, psychologists, psychiatrists, social workers, educators, geneticists, physiotherapists, occupational therapists and CI advocates..$^{[39-41]}$

\section{Patient selection for cochlear implantation}

Patient candidacy criteria are used as a guide to determine a patient's eligibility for a CI. The patient candidacy criteria for cochlear implantation are comprehensive and meticulous, in the best interests of appropriate, cost-effective patient care, as cochlear implantation is an invasive procedure with high stakes and expectations. Furthermore, given the significant expense of CI devices, within a LMIC such as SA with its limited resources, high disease burden and funding constraints, it is understandable that various healthcare priorities must be weighed against one another. This meticulousness aims to ensure cost-effective cochlear implantation in order to optimise outcomes and use, and minimise ineffective expenditure due to $\mathrm{CI}$ non-use or poor outcomes. Furthermore, while determining CI candidacy, the CI team should strategise the best intervention for the candidate's hearing loss in both ears ${ }^{[39]}$ - whether the patient will benefit most from bilateral implantation (two CIs implanted either sequentially or simultaneously) or bimodal implantation (one hearing aid and one $\mathrm{CI}$ ). Table 1 summarises the candidacy criteria used to guide cochlear implantation patient selection in SA.

\section{Conclusion}

A CI is an acknowledged, successful and cost-effective implantable device that has revolutionised the ability of healthcare practitioners to restore hearing, and that has the ability to transform the lives of individuals with severe-profound SNHL. The current status of cochlear implantation in SA will be discussed in part two of this series.

\section{Declaration. None.}

Acknowledgments. The authors appreciatively acknowledge Tamara van Zyl (South African Cochlear Implant Group (SACIG) secretary) for her assistance and valued support with the SACIG annual report statistics. Author contributions. AB drafted the article. All authors read, edited and approved the article. 


\section{Table 1. Candidacy criteria for cochlear implantation patient selection in South Africa ${ }^{[39]}$}

Audiological criteria:

- individuals with bilateral moderate-to-profound SNHL who derive minimal to no benefit from bilaterally fitted hearing aids with aided word recognition score of $<40 \%$ in the ear to be implanted

- paediatric population: children aged $\geq 6$ months with moderate (severe)-to-profound SNHL and insufficient development of spoken language

- adult population: individuals aged $\geq 18$ years (no upper age limit)

- older children and adults with prelingual or perilingual severe-profound SNHL, with spoken language as their primary communication mode and who obtain minimal to no benefit from bilaterally fitted hearing aids

Medical criteria:

- intact auditory nerve

- patency of the cochlea for electrode insertion should be sufficient

- implantation procedure should be able to be done with minimal risk to the patient

Rehabilitative criteria:

- high level of motivation for the $\mathrm{CI}$ and commitment towards the long-term rehabilitation process

- appropriate levels of expectation regarding the possible benefits of a CI

- accessibility to CI programme for audiological and rehabilitative management

Financial criteria:

- candidate/family should demonstrate the financial ability to support the long-term maintenance of the CI device and the rehabilitation process

$\mathrm{SNHL}=$ sensorineural hearing loss; $\mathrm{CI}=$ cochlear implant.

Funding. This project was funded with assistance from the Andrew W Mellon Foundation's grant entitled 'Supra-institutional initiative on the advancement of black South Africans within the arts, humanities, and social sciences' grant number G-41500687.

Conflicts of interest. None.

1. Cunningham T, Tucci D. Hearing loss in adults. N Engl J Med 2017;377(25):2465-2473. https://do org/10.1056/NEJMra161660

2. World Health Organization. Addressing the rising prevalence of hearing loss, 2018. https://apps.who.int/ iris/bitstream/handle/10665/260336/9789241550260-eng.pdf?sequence=1\&ua=1 (accessed 4 June 2019). Fagan JJ, Jacobs M. Survey of ENT services in Africa: Need for a comprehensive intervention. Glob Health Action 2009;2(1):1-7. https://doi.org/10.3402/gha.v2i0.1932

4. Olusanya BO, Somefun AO, Swanepoel DW. The need for standardisation of methods for worldwide infant hearing screening: A systematic review. Laryngoscope 2008;118(10):1830-1836. https://doi. org/10.1097/MLG.0b013e31817d755

5. World Health Organization. WHO Global estimates on prevalence of hearing loss, 2018. https://www.who int/pbd/deafness/estimates/en/ (accessed 2 June 2019)

6. Burke MJ, Shenton RC, Taylor MJ. The economics of screening infants at risk of hearing impairment: An international analysis. Int J Pediatr Otorhinolaryngol 2012;76(2):212-218. https://doi.org/10.1016/j. ijporl.2011.11.004

7. Karchmer MA, Allen TE. The functional assessment of deaf and hard of hearing students. Am Ann Deaf 1999;144(2):68-77. https://doi.org/10.1353/aad.2012.0468

8. Olusanya BO. Neonatal hearing screening and intervention in resource-limited settings: An overview. Arch Dis Child 2012;97(7):654-665. https://doi.org/10.1136/archdischild-2012-301786

9. Venail F, Vieu A, Artieres F, Mondain M, Uziel A. Educational and employment achievements in prelingually deaf children who receive cochlear implants. Arch Otolaryngol Head Neck Surg in prelingually deaf children who receive cochlear implan
2010;136(4):366-372. https://doi:org/10.1001/archoto.2010.31

10. Storbeck C. Childhood hearing loss in the developing world. Int J Child Health Nutrition 2012;1(1):59-65. https://doi.org/10.6000/1929-4247.2012.01.01.07

11. World Health Organization. World report on hearing, 2021. Geneva: WHO, 2021. https://www.who.int/ publications/i/item/world-report-on-hearing (accessed 8 March 2021).

publications $/ \mathrm{i} /$ item/world-report-on-hearing (accessed 8 March 2021).
12. Louw C, Swanepoel W, Eikelboom, RH, Hugo J. Prevalence of hearing loss at primary health care clinics in . Louw C, Swanepoel W, Eikelboom, RH, Hugo J. Prevalence of hearing loss at primary h
South Africa. Afr Health Sci 2018;18(2):313-320. https://doi.org/10.4314/ahs.v18i2.16

13. Statistics South Africa. Census 2011: Profile of persons with disabilities in South Africa, report
natical 03-01-59, 2011. Pretoria: StatsSA, 2011. http://www.statssa.gov.za/publications/Report-03-01-59/
03 03-01-59, 2011. Pretoria: StatsSA, 2011. http://
Report-03-01-592011.pdf (accessed 11 March 2021).

14. Olusanya BO. Priorities for early hearing detection and in

15. Saunders J Bas D. Cocher in attitudes and recommendations for best practice. Otolaryngol Head Neck Surg 2011;145(1):74-79. https:// doi.org/10.1177/0194599811401343

16. Kral A, O'Donoghue GM. Profound deafness in childhood. N Engl J Med 2010;363(15):1438-1450. https://doi.org/10.1056/NEJMra0911225

17. Westerberg BD, Lee PK, Lukwago L, Zaramba S, Bubikere S, Stewart I. Cross-sectional survey of hearing impairment and ear disease in Uganda. J Otolaryngol Head Neck Surg 2008;37(6):753-758.

18. World Health Organization. Development of a new Health Assembly resolution and action plan for prevention of deafness and hearing loss 2016. Geneva: WHO, 2016. http://apps.who.int/gb/ebwha/pdf_ files/EB139/B139_5-en.pdf (accessed 2 June 2019)

19. Wilson BS, Dorman MF. Cochlear implants: A remarkable past and a brilliant future. Hear Res 2008;242(1-2):3-21. https://doi.org/10.1016/j.heares.2008.06.005

20. National Institute on Deafness and Other Communication Disorders. Cochlear Implants. Bethesda: NIDCD, 2021. https://www.nidcd.nih.gov/health/cochlear-implants (accessed 17 December 2020).

21. Sharma A, Dorman MF, Spahr AJ. A sensitive period for the development of the central auditory system in children with cochlear implants: Implications for age of implantation. Ear Hear 2002;23(6):532-539. https://doi.org/10.1097/00003446-200212000-00004
22. Leigh J, Dettman S, Dowell R, Briggs R. Communication development in children who receive a cochlear implant by 12 months of age. Otol Neurotol 2013;34(3):443-450. https://doi.org/10.1097/ MAO.0b013e3182814d2c

23. Ching TYC, Dillon H, Marnane V, et al. Outcomes of early- and late-identified children at 3 years of age: Findings from a prospective population-based study. Ear Hear 2013;34(5):535-552. https://doi org/10.1097/AUD.0b013e3182857718

24. Zwolan TA, Ashbaugh CM, Alarfaj A, et al. Pediatric cochlear implant patient performance as a function of age at implantation. Otol Neurotol 2004;25(2):112-120. https://doi.org/10.1097/00129492-
200403000-00006

25. Svirsky MA, Teoh S, Neuburger H. Development of language and speech perception in congenitally, profoundly deaf children as a function of age at cochlear implantation. Audiol Neuro-Oto 2004;9(4):224-233. https://doi.org/10.1159/000078392

26. Manrique M, Cervera-paz FJ, Huarte A, Molina, M. Advantages of cochlear implantation in prelingual deaf children before 2 years of age when compared with later implantation. Laryngoscope 2004;114(8):1462-1469. https://doi.org/10.1097/00005537-200408000-00027

27. May-Mederake B. Early intervention and assessment of speech and language development in young children with cochlear implants. Int J Pediatr Otorhinolaryngol 2012;76(7):939-946. https://doi org/10.1016/j.ijporl.2012.02.051

28. Sach TH, Whynes DK. Paediatric cochlear implantation: The views of parents. Int J Audiol 2005;44(7):400-407. https://doi.org/10.1080/14992020500146500

29. Hirschfelder A, Gräbel S, Olze H. The impact of cochlear implantation on quality of life: The role of audiologic performance and variables. Otolaryngol Head Neck Surg 2008;138:357-362. https://doi org/10.1016/j.otohns.2007.10.019

30. Chen S, Karamy B, Shipp D, Nedzelski J, Chen J, Lin V. Assessment of the psychosocial impacts of cochlear implants on adult recipients and their partners. Cochlear Implants Int 2016;17(2):90-97 https://doi.org/10.1080/14670100.2015.1102456

31. Sladen DP, Peterson A, Schmitt M, et al. Health-related quality of life outcomes following adult cochlea implantation: A prospective cohort study. Cochlear Implants Int 2017;18(3):130-135. https://doi.org/ $0.1080 / 14670100.2017 .1293203$

32. Mosnier I, Bebear JP, Marx M, et al. Improvement of cognitive function after cochlear implantation in elderly patients. JAMA Otolaryngol Head Neck Surg 2015;141(5):442-450. https://doi.org/10.1001/ jamaoto.2015.129

33. Buchman CA, Gifford RH, Haynes DS, et al. Unilateral cochlear implants for severe, profound, or moderate sloping to profound bilateral sensorineural hearing loss: A systematic review and consensus statements. JAMA Otalaryngol Head Neck Surg 2020;146(10):942-953. https://doi.org/10.1001/ statements. JAMA

34. Wolfe J. Cochlear Implants: Audiologic Management and Considerations for Implantable Hearing Devices. San Diego, CA: Plural Publishing, 2020.

35. Eisenberg LS. The contributions of William F. House to the field of implantable auditory devices. Hear Res 2015;322:52-56. https://doi.org/10.1016/j.heares.2014.08.003

36. Henkel G. History of the cochlear implant. ENT Today, 2013. https://www.enttoday.org/article/historyof-the-cochlear-implant (accessed 4 August 2021).

37. Emmett SD, Tucci DL, Smith M, et al. GDP matters: Cost effectiveness of cochlear implantation an Deaf education in sub-Saharan Africa. Otol Neurotol 2015;36(8):1357-1365. https://doi.org/10.1097/ MAO.0000000000000823

38. Parikh SR, Machleder DJ, Chobot-Rodd J, et al. Building a multidisciplinary cochlear implant team. Einstein J Biol Med 2004;21(1):19-24. https://doi.org/10.23861/EJBM200421456

39. South African Cochlear Implant Group. Quality standards for cochlear implantation in South Africa, 2020. http://www.sacig.org.za/wp-content/uploads/2020/01/SACIG-Guidelines.pdf (accessed 20 May 2020).

40. Martin J, Raine CH. Quality standards for cochlear implantation in children and young adults. Cochlear Martin J, Raine CH. Quality standards for cochlear implantation in children and young adults.
Implants Int 2013;14(Suppl 2):S13-S20. https://doi.org/10.1179/1467010013Z.00000000099

41. Müller J, Raine CH. Quality standards for adult cochlear implantation. Cochlear Implants Int 2013;14(Suppl 2):S6-S12. https://doi.org/10.1179/1467010013Z.00000000097 